Published in final edited form as:

AIDS Behav. 2020 October ; 24(10): 2885-2894. doi:10.1007/s10461-020-02839-9.

\title{
Social Support Mitigates Negative Impact of Food Insecurity on Antiretroviral Adherence Among Postpartum Women in Western Kenya
}

\author{
Mira Wang ${ }^{1}$, Joshua D. Miller ${ }^{1}$, Shalean M. Collins ${ }^{1}$, Marianne V. Santoso ${ }^{1}$, Pauline \\ Wekesa $^{2}$, Hideaki Okochi ${ }^{3}$, Maricianah Onono ${ }^{2}$, Sheri D. Weiser ${ }^{3}$, Monica Gandhi ${ }^{3}$, Sera L. \\ Young ${ }^{1,4}$ \\ ${ }^{1}$ Department Anthropology, Program in Global Health, Northwestern University, Evanston, IL \\ ${ }^{2}$ Family Aids Care and Education Services (FACES), Kenya Medical Research Institute, Kisumu, \\ Kenya \\ ${ }^{3}$ Department of Medicine, Division of HIV, Infectious Diseases, and Global Medicine, University of \\ California San Francisco, San Francisco, CA \\ ${ }^{4}$ Institute for Policy Research, Northwestern University, Evanston, IL
}

\section{Abstract}

Food insecurity (FI), low social support, and low health-related quality of life (HRQoL) are associated with self-reported nonadherence to antiretroviral therapy (ART) among postpartum women, but these relationships have not been evaluated using objective adherence indicators. Hair samples were therefore analyzed among 83 postpartum Kenyan women living with HIV on efavirenz and nevirapine ART drug regimens in an observational cohort (NCT02974972). FI (027), social support (0-40), and HRQoL (8-40) in the prior month were also assessed. In multivariable models, each point increase in FI and decrease in HRQoL were associated with a $45.1 \%$ (95\% CI: $-64.3 \%,-15.6 \%)$ and $10.5 \%$ decrease (95\% CI: $1.0 \%, 22.1 \%$ ) in hair ART drug concentrations respectively, when social support was held constant. A significant interaction between social support and FI $(\beta=0.02, p=0.017)$ indicated that greater social support was predicted to mitigate the negative impacts of FI on ART adherence. Addressing these modifiable barriers could improve ART adherence during this critical period.

\section{Keywords}

antiretroviral adherence; hair ART drug concentrations; food insecurity; social support; postpartum

\footnotetext{
Terms of use and reuse: academic research for non-commercial purposes, see here for full terms. https://www.springer.com/aamterms-v1

Corresponding Author: Sera L. Young, 1819 Hinman Ave. Evanston, IL 60208, Telephone: +1 (847) 467-2174, sera.young@northwestern.edu.

Publisher's Disclaimer: This Author Accepted Manuscript is a PDF file of an unedited peer-reviewed manuscript that has been accepted for publication but has not been copyedited or corrected. The official version of record that is published in the journal is kept up to date and so may therefore differ from this version.
} 


\section{INTRODUCTION}

Adherence to antiretroviral treatment (ART) is critical for suppressing viral loads and maintaining the health of people living with HIV (1). Suboptimal adherence can lead to poor treatment efficacy and negative health outcomes, including increased levels of inflammation, virologic failure, co-infections, and death (1-3). Patients may also experience an increased likelihood of viral drug resistance and treatment failure (4). In low-resource settings, where diagnostic tests for drug resistance and late-stage ART regimens may be prohibitively expensive or difficult to procure, maintaining optimal ART adherence to first-line medications is critical for long-term health $(4,5)$.

Optimal adherence is particularly important during the perinatal period for mothers and their infants. Sustained ART adherence during postpartum is associated with a lower risk of virologic failure and mother-to-child HIV transmission (6-8). Previous studies have identified numerous barriers to optimal ART adherence during postpartum across the socioecological framework, from distal interpersonal and structural factors to individuallevel determinants. Interpersonal and structural barriers include lack of support from clinic staff and/or relatives, HIV-related stigma, limited access to health services, long wait times for care, limited communication and coordination among healthcare workers and services, poor health information systems, and gaps in provider treatment (9-12). Previous studies have also attributed decreases in postpartum ART adherence to reduced maternal concern about vertical transmission after pregnancy, perhaps due to less intensive clinical care than in the antepartum period, or lack of provider communication about the risk of vertical transmission from breastfeeding $(6,13,14)$.

Individual-level barriers to optimal ART adherence include lower education level lack of knowledge about HIV, and HIV-related fears of job loss and/or loss of family status (9-12). During postpartum, physical, economic, and emotional stressors related to caring for an infant and other children, as well as unplanned pregnancy, advanced HIV disease status, higher HIV-RNA viral load, and side effects of ART (e.g. fatigue, vomiting, and diarrhea) are also associated with lower ART adherence (6,11-15). Further, low quality of life (2931), depression (32), low socioeconomic status (33), stress (34), HIV stigma (35), and sociodemographic factors (e.g. age, number of dependents, marital status) (18) have been shown to be associated with lower ART adherence. Additional individual-level barriers include drug use, greater drug regimen frequency, increased pill burden, and treatment fatigue $(6,7,13,14)$.

A growing body of research has identified food insecurity (FI) as a barrier to optimal ART adherence (13,16-24). In a previous meta-analysis, a statistically significant association was found between food insecurity (FI) and ART non-adherence; nine of the ten included studies reported increased odds of ART non-adherence among food-insecure households (16). Multiple potential pathways linking these phenomena have been proposed, including: exacerbated negative side effects of ART in the absence of food, leading individuals to skip doses; belief among some individuals that they should skip doses or delay ART initiation if they cannot afford the added nutritional burden; competing demands between costs of food and medical expenses; and increased likelihood of forgetting ART drug doses while working 
for food $(13,18,25)$. ART may also exacerbate the experience of food insecurity (FI) itself; women with HIV have reported an increase in appetite after ART initiation $(16,22,25)$.

The negative impacts of food insecurity on ART adherence may be mitigated by social support, as it has for other health-related outcomes, including depression (26). Multiple studies have directly linked high social support to increased ART adherence, but none have explored its potential interaction with other predictors despite several plausible pathways $(6,27,28)$. For example, family members and/or peers could remind a person living with HIV to take ART, attend appointments with providers, or brainstorm ways that the person could disclose HIV status with a partner (28).

The preponderance of previous studies, however, have relied on subjective metrics of adherence, including self-report, pharmacy records, and/or pill counts (16). These indicators of adherence are limited by social desirability bias, question misinterpretation, poor recall, open pharmacy refill systems, and an ability to manipulate pill counts $(33,36-38)$. Given these limitations, objective biomarker data on ART adherence surpasses subjective measures in predicting treatment outcomes. Previous work has demonstrated that biomarkers provide more robust and reliable data on ART adherence than self-report in predicting treatment outcomes (39-46). Moreover, self-reported adherence is often poorly correlated with objective biomarkers of adherence, such as ART drug levels in dried blood spots (DBS) and hair $(37,38,47,48)$. Objective markers of adherence include assays of drug levels in a variety of biomatrices, including plasma, DBS, urine and hair. But measurement of drug levels in plasma or DBS requires phlebotomy and plasma levels do not capture long-term adherence $(47,49)$. Hair ART drug concentrations, however, can overcome some of these limitations; hair analysis can measure adherence in the prior month and has been shown to be effective and feasible for use by local research staff and participants in rural Kenya $(47,48)$. This novel metric has also been validated against relevant health outcomes. For example, previous studies have demonstrated that hair ART drug levels are strong predictors of virologic suppression in multiple settings, including women of childbearing age with HIV $(39,40,42,50)$. As such, local capacity to measure hair ART drug concentrations is being expanded in resource-limited settings (51).

Therefore, our first objective was to identify predictors of ART adherence using hair ART drug concentrations among postpartum women in the Nyanza region of Kenya. We hypothesized that increased food insecurity, lower quality of life, and depression would be associated with decreased ART adherence, operationalized as lower hair ART drug concentrations. The second objective was to explore the relationship between social support and other factors impacting ART adherence. We hypothesized that social support would modify the deleterious effects of food insecurity, quality of life, and depression on adherence.

\section{METHODS}

\section{Study Design \& Population}

Data are from Pith Moromo, a longitudinal observational cohort study designed to explore the impacts of HIV and food insecurity during the first 1000 days (i.e. one year prior to 
delivery and two years postpartum) (NCT02974972). Pregnant women of mixed HIV status $(n=371)$ were recruited from Family AIDS Care and Educational Services (FACES) clinics across seven urban, peri-urban, and rural areas (Kisumu, Macalder, Migori, Nyahera, Nyamaraga, Ongo, Rongo) in Nyanza region, Kenya (near Lake Victoria) between September 2014 and June 2015. FACES clinics deliver basic health services to all adults as well as integrated, comprehensive HIV treatment and prevention services.

Women were eligible for inclusion if they were within their first seven months of pregnancy (assessed using reported last menstrual period) and intended to live in the catchment area until their infant(s) reached at least nine months of age. Quota sampling was used to achieve equal numbers of pregnant women living with and without HIV by tertiles of food insecurity, as assessed using the nine-item Individual Food Insecurity Access Scale (IFIAS) (low 0-9, moderate 10-18, severe 19-27) (52). Women living with HIV were oversampled [approximately $6.9 \%$ of women of reproductive age in western Kenya live with HIV (53)] to detect differences in primary study outcomes (e.g. maternal BMI) by HIV status at a power of 0.8. All women living with HIV were prescribed antiretroviral therapy in accordance with national guidelines.

Participants were followed from approximately 30 weeks pregnancy to nine months postpartum. Of the 371 women enrolled in Pith Moromo at baseline, 187 were living with HIV. At nine months postpartum, 134 of these women living with HIV were interviewed and 89 agreed to provide hair samples for assessing ART adherence. The majority of women who provided hair samples received either efavirenz- or nevirapine-based ART drug regimens, although six women were on lopinavir- and/or ritonavir-based regimens. Given this small sample size, we therefore restrict our analysis to the 83 women who provided hair samples at the nine-month visit and received either efavirenz- or nevirapine-based ART drug regimens (Figure 1).

\section{Study Setting}

The Nyanza region is one of the most food insecure in Kenya and has the highest prevalence of HIV in the country $(54,55)$. In 2018, four of the six counties in Nyanza region had an HIV prevalence above $11.1 \%$, compared to $4.9 \%$ nationally (55). Further, in 2015, mother-tochild transmission rates of HIV in Kenya increased from $4.8 \%$ after 6 weeks of breastfeeding to $8.3 \%$ at the end of breastfeeding, indicating a need to support women with ART adherence throughout the postpartum period (8).

\section{Data Collection}

Study outcome: Hair ART drug concentrations-At nine months postpartum, study nurses collected hair samples close to the scalp from the back of the head. Samples were stored in aluminum foil at room temperature and sent to the University of California San Francisco (UCSF) Hair Analytical Laboratory for analysis of ART drug concentrations. Hair samples were 1 centimeter $(\mathrm{cm})$ from the scalp and then cut into 1-millimeter sections for ART drug extraction. After ART drug extraction, nevirapine and efavirenz levels in the hair were quantified via validated liquid chromatography/tandem mass spectrometry (LCMS/MS, Shimadzu Prominence UFLC system coupled with Sciex API5000) based methods 
$(39,51)$. All of the UCSF Hair Analytical Laboratory's analytic methods have been peer reviewed and approved by the NIH's Division of AIDS Clinical Pharmacology and Quality Assurance Program (61). ART drug concentrations were divided by the amount of weighed hair (approximately 2 milligrams) to standardize concentrations. Given that hair grows at roughly $1 \mathrm{~cm} /$ month, concentrations reflect ART drug intake in the month prior to collection. Efavirenz or nevirapine concentrations were logarithmically transformed to reduce skewness and improve comparability across regimens (48). A small constant was added before transformation to ensure that differences between low ART drug concentrations were not overstated (48). Continuous hair ART drug concentrations were used to represent adherence, where higher concentrations represent greater ART adherence. Previous studies have shown that ART drug concentrations have a dose-response relationship with virologic outcomes of clinical significance, although no established thresholds exist for distinguishing between adherent and non-adherent individuals (39).

Exposures of interest—Data on food insecurity, social support, and health-related quality of life were collected at nine months postpartum and captured experiences in the prior month. The Individual Food Insecurity Access Scale (range: 0-27), a modified version of the Household Food Insecurity Access Scale, consists of nine questions, each of which has four response options (never $=0$, rarely $=1$, sometimes $=2$, often=3) (52). Severe food insecurity is based on an algorithm developed by Coates et al. (52). Higher IFIAS scores indicate higher levels of food insecurity (52). Perceived social support (range: 0-40), was assessed using the modified Duke-UNC Functional Social Support Questionnaire, which measures functional elements of social support; higher scores represent higher levels of social support (56). Finally, the Quality of Life Short Form (SF)-8 (range: 8-40) is a modified tool that uses one question to measure each of the SF-36's eight domains related to quality of life: physical functioning, limitations due to physical health problems, bodily pain, general health, energy/fatigue, social functioning, limitations due to emotional problems, and psychological well-being (57). Respondents indicate severity using a five-point scale, in which a rating of 1 indicates highly negative effects on quality of life and 5 indicates limited negative effects on quality of life; higher scores indicate higher health-related quality of life.

Other social and behavioral covariates of interest were also measured at nine months postpartum, including probable maternal depression [Center for Epidemiologic Studies Depression Scale (CES-D), 0-60] (58), HIV stigma (HIV Stigma Mechanism Measure) (59), and gender-based violence (WHO Multi-country Study on Women's Health and Domestic Violence Against Women Questionnaire) (60).

Potential confounders-Survey data were collected by local, clinic-based nurses using electronic surveys at two time points: during the index pregnancy and at 9 months postpartum. Sociodemographic information, such as marital status, maternal age, education level, primigravidity, and household census data were based on maternal recall at baseline. HIV status was assessed by study nurses at all time points using colloidal gold rapid test. A wealth measure was created by performing a principal component analysis on reported household assets at nine months postpartum. A dependency ratio was calculated by dividing the number of dependents (i.e. children younger than 15 years and adults older than 64) by 
the number of adults in the household. At nine months postpartum, women living with HIV were asked to list all individuals to whom they had disclosed their status.

\section{Data Analysis}

Descriptive statistics were performed using Stata 14.0. Exposures of interest that were associated with ART drug concentration in bivariate linear regressions $(p<0.2)$ were included with all potential confounders in a multivariable linear regression. To achieve a parsimonious model, variables were eliminated if they lowered model fit (i.e. reduced root mean square error). To assess the potential moderating role of social support on ART adherence, we explored interactions between social support and other salient predictors, as identified in bivariate analyses [62].

\section{Ethics}

All study procedures were approved by institutional review boards at Kenya Medical Research Institute, Cornell University, and Northwestern University. All participants provided written informed consent at enrollment.

\section{RESULTS}

\section{Cohort Characteristics}

A majority of women included for analysis were married (89.2\%), had a median age of 26.0 years, and a dependency ratio of 0.7 (Table I). Most participants (65.9\%) finished primary school and were Luo $(96.2 \%)$. On average, participants had to travel 67.8 minutes $( \pm 114.3)$ to the nearest health clinic. Mean maternal food insecurity score was $10.0( \pm 5.2)$. Maternal sociodemographic characteristics were similar between individuals on efavirenz- and nevirapine-based ART drug regimens (Table I).

Participants were more reluctant to give hair samples than any other biomarker collected in this study. Forty-five women declined to give hair samples (Figure 1) due to suspicions of witchcraft and/or government surveillance. Individuals on these regimens who agreed to provide hair samples $(n=89)$ were similar to women who did not provide samples $(n=45)$ across most characteristics, although women who declined to provide hair samples had a higher household dependency ratio and lower perceived social support (Supplementary Table 1).

\section{Predictors of ART Drug Adherence}

The median concentration of efavirenz in hair samples ( $\mathrm{n}=58)$ was $3.01 \mathrm{ng} / \mathrm{mg}$ (IQR 0.25 11.0), and $60.0 \mathrm{ng} / \mathrm{mg}$ (IQR 33.4 - 79.7) for nevirapine $(\mathrm{n}=25)$ (Table I). In exploratory bivariate analyses, food insecurity $(\beta=-0.16)$ was inversely associated with ART drug concentrations and quality of life $(\beta=0.16)$ was positively associated with higher hair ART drug concentrations. Maternal probable depression and disclosure of HIV status to a partner were not significantly associated with higher hair ART drug concentrations. Other significant correlates of higher ART drug levels included increased social support $(\beta=0.14)$, greater wealth $(\beta=0.27)$, and new HIV diagnosis at enrollment (vs. known positive) ( $\beta=$ $-1.07)$ (Table II). 
In the final multivariable model, increased food insecurity $(\beta=-0.60)$, lower quality of life ( $\beta=0.10)$, and new HIV diagnosis at enrollment (vs. known positive) $(\beta=-0.94)$ were significantly associated $(p<0.05)$ with decreased hair ART drug concentrations (Table III). Each point higher on the food insecurity scale and each point lower on the HRQoL scale was associated with a $45.1 \%$ (95\% CI: $-64.3 \%,-15.6 \%)$ and $10.5 \%$ decrease (95\% CI: $1.0 \%$, $22.1 \%$ ) in hair ART drug levels, respectively.

To our second objective, we found that social support significantly moderated the impact of food insecurity on hair ART drug levels $(\beta=0.02)$ (Table III). Specifically, we found a significant multiplicative interaction between food insecurity and social support, such that individuals with low social support were predicted to more acutely experience the negative impacts of food insecurity on ART drug adherence. In other words, at all levels of food insecurity, the impact of food insecurity on ART adherence was dependent upon an individual's social support score (Figure 2).

\section{DISCUSSION}

Higher food insecurity and lower quality of life were deleterious to ART adherence, as objectively recorded by hair ART drug concentration. Further, we found that social support attenuated the negative impacts of food insecurity on ART adherence.

In our final model (Table III), higher food insecurity had a significant and independent association with decreased ART drug concentrations in hair. This is consistent with other studies using subjective adherence measures, which have attributed sub-optimal adherence to experiences of hunger, food insecurity, and exacerbated side effects related to ART $(13,16,18-20,25,63)$. This may occur because ART can increase appetite among patients, who may require food for optimal pharmacokinetic levels (25). Moreover, patients have reported worsened side effects of ART in the absence of food, competing demands between the cost of food and medical expenses, and a belief that one should abstain from HIV treatment if the added nutritional burden is unaffordable (25).

We also found that quality of life was positively associated with ART drug concentrations in hair (Table III). This finding is also consistent with previous studies of self-reported adherence. For instance, prior research in Spain (29), the U.S. (30), and South Africa (31) found that increased health-related quality of life was associated with higher rates of ART adherence. Although each study used a different quality of life scale, all tools defined quality of life in terms of perceived physical and mental health, barriers to physical and emotional roles in everyday life, social functioning, and pain, suggesting consistency across study findings. Further, the U.S. cohort study found an association between improved physical and mental health-related quality of life scores and improved virologic outcomes (30).

The buffering effect of social support on food insecurity was particularly important (Figure 2): the negative impact on food insecurity on ART drug concentrations was attenuated by increased social support (Table III, Figure 2). In other words, although women experiencing greater food insecurity had lower hair ART drug concentrations compared to women experiencing less severe food insecurity, among women reporting the same food insecurity 
score, the impact of food insecurity on adherence differed significantly by perceived social support. Although social support has been demonstrated to buffer against the negative consequences of a number of physical and physiologic stressors (64-66), this is the first study to our knowledge to report a significant interaction between food insecurity and social support on ART adherence. This adds to previous work that has identified social support as an effect modifier for food insecurity on depression $(26,67,68)$, and for substance use on ART adherence (69). Social support may act as an effect modifier on the relationship between food insecurity and ART adherence in three different ways: emotional, informational, and appraisal. For example, family members and peers may provide emotional social support to reduce the psychosocial stress associated with FI. Informational social support, such as giving practical advice and insights into available resources, and appraisal social support, such as reminding an individual about the qualities she has that enable her to overcome barriers, may also help one remain adherent to ART despite FI [70].

In this analysis, we controlled for potential confounders, including new diagnosis of HIV at enrollment, which was significantly associated with decreased ART concentration in hair. Women who had a new HIV diagnosis at the start of this study were more likely to exhibit lower hair ART concentrations compared to women who had known positive HIV status at enrollment. Lower adherence at this stage may be attributed to inner turmoil related to the new diagnosis. In a qualitative study in Rwanda, ART-naïve and ART-experienced women reported a struggle to adhere to their medication when first prescribed, due to a sense of hopelessness upon learning their HIV status and the need to take lifelong ART, a belief that they will die regardless of treatment, and suicidal ideation $(11,12)$.

A significant strength of this study is the use of ART drug concentration in hair as a biomarker of adherence, which is a highly sensitive and selective tool that can be effectively and feasibly applied in low-resource settings $(42,47,48)$. Limitations include a relatively small sample size $(n=83)$, which may limit generalizability beyond Nyanza, Kenya, and which may explain the absence of significant relationships between adherence and maternal probable depression, HIV stigma, maternal stress, and disclosure of HIV status to partners. In a recent meta-analysis of HIV adherence and depression, the median number of enrolled participants in each study was over 150 (71). Though previous studies have found systemlevel factors, such as access to health care services, as well as other individual-level factors, such as age of children under a woman's care and whether a pregnancy was planned or unplanned, as significant correlates with adherence, this study did not collect these data and so were unable to test these factors $(9-12,15)$. In addition, though study personnel asked women to disclose the date of their first positive HIV test, too few women answered this question, necessarily excluding this factor from analysis (15). Further, about one-third of participants with HIV $(n=45)$ declined to give hair samples. Given the higher cost and more invasive nature of blood samples to measure adherence, future research should explore how to increase uptake of hair sample collection. Finally, we only looked at hair samples for two types of ART anchor drugs, efavirenz and nevirapine, at one time point. It is unknown whether factors related to improved adherence would vary depending on other kinds of ART regimens and the particular burdens they place on patients, or with timing of measurement relative to pregnancy. Overall, however, these findings are noteworthy given the paucity of 
literature on the link between food insecurity and adherence using objective metrics among postpartum women and can be used to drive further research and intervention development.

\title{
CONCLUSION
}

To our knowledge, this is one of the first studies to analyze the link between food insecurity and ART adherence using hair ART drug concentration as a biomarker, and the first to identify social support as a moderating factor of the negative effect of food insecurity on adherence. Further, this is the first study to identify a relationship between health-related quality of life and ART adherence.

The results of this study suggest that multi-level ART adherence-related programs and policies that promote food security, overall health-related quality of life, and social support are needed among perinatal and postpartum women. More research is needed to understand the mechanisms through which social support mitigates the negative effects of food insecurity on adherence. Interventions designed to improve adherence may also benefit from using hair ART drug concentrations to measure adherence to monitor and evaluate their impacts.

\section{Supplementary Material}

Refer to Web version on PubMed Central for supplementary material.

\section{ACKNOWLEDGMENTS}

\begin{abstract}
We thank the Kenya Medical Research Institute (KEMRI) for providing space within the FACES clinics for the work to be conducted, logistic support to conduct this research, and oversight in Kenya. We would also like to warmly thank study nurses and study trackers, as well as the mothers and their infants who participated in this study. Further, we thank the anonymous reviewers in the peer review process, whose comments significantly improved our analyses. The study (NCT02974972) was supported by the National Institute of Mental Health (NIH/ NIMH K01 MH098902) and the National Institute of Allergy and Infectious Diseases (NIAID 2RO1AI098472).
\end{abstract}

Sources of Support: NIH/NIMH K01MH098902 and NIAID 2R01AI098472.

\section{REFERENCES}

1. Haubrich RH, Little SJ, Currier JS, Forthal DN, Kemper CA, Beall GN, et al. The value of patientreported adherence to antiretroviral therapy in predicting virologic and immunologic response: AIDS. 1999 6;13(9):1099-107. [PubMed: 10397541]

2. Castillo-Mancilla JR, Brown TT, Erlandson KM, Palella FJ, Gardner EM, Macatangay BJC, et al. Suboptimal Adherence to Combination Antiretroviral Therapy Is Associated With Higher Levels of Inflammation Despite HIV Suppression. Clin Infect Dis. 201612 15;63(12):1661-7. [PubMed: 27660234]

3. Walson JL, Brown ER, Otieno PA, Mbori-Ngacha DA, Wariua G, Obimbo EM, et al. Morbidity Among HIV-1-Infected Mothers in Kenya: Prevalence and Correlates of Illness During 2-Year Postpartum Follow-Up. JAIDS J Acquir Immune Defic Syndr. 2007 10;46(2):208-15. [PubMed: 17667334]

4. Uy J, Armon C, Buchacz K, Wood K, Brooks JT. Initiation of HAART at Higher CD4 Cell Counts Is Associated With a Lower Frequency of Antiretroviral Drug Resistance Mutations at Virologic Failure: JAIDS J Acquir Immune Defic Syndr. 2009 8;51(4):450-3. [PubMed: 19474757]

5. Vella S, Schwartländer B, Sow SP, Eholie SP, Murphy RL. The history of antiretroviral therapy and of its implementation in resource-limited areas of the world: AIDS. 2012 6;26(10):1231-41. 
6. Nachega JB, Uthman OA, Anderson J, Peltzer K, Wampold S, Cotton MF, et al. Adherence to antiretroviral therapy during and after pregnancy in low-income, middle-income, and high-income countries: a systematic review and meta-analysis. AIDS. 2012 10;26(16):2039-52. [PubMed: 22951634]

7. Onoya D, Sineke T, Brennan AT, Long L, Fox MP. Timing of pregnancy, postpartum risk of virologic failure and loss to follow-up among HIV-positive women: AIDS. 2017 7;31(11):1593602 .

8. On the Fast-Track to an AIDS-free generation. :108.

9. Hodgson I, Plummer ML, Konopka SN, Colvin CJ, Jonas E, Albertini J, et al. A Systematic Review of Individual and Contextual Factors Affecting ART Initiation, Adherence, and Retention for HIVInfected Pregnant and Postpartum Women. Newell M-L, editor. PLoS ONE. 201411 5;9(11):e111421.

10. Colvin CJ, Konopka S, Chalker JC, Jonas E, Albertini J, Amzel A, et al. A Systematic Review of Health System Barriers and Enablers for Antiretroviral Therapy (ART) for HIV-Infected Pregnant and Postpartum Women. Fischer G, editor. PLoS ONE. 201410 10;9(10):e108150.

11. Gill MM, Umutoni A, Hoffman HJ, Ndatimana D, Ndayisaba GF, Kibitenga S, et al. Understanding Antiretroviral Treatment Adherence Among HIV-Positive Women at Four Postpartum Time Intervals: Qualitative Results from the Kabeho Study in Rwanda. AIDS Patient Care STDs. 2017 4;31(4):153-66. [PubMed: 28358624]

12. Vitalis D. Factors affecting antiretroviral therapy adherence among HIV-positive pregnant and postpartum women: an adapted systematic review. :8.

13. Vitalis D, Hill Z. Antiretroviral Adherence Perspectives of Pregnant and Postpartum Women in Guyana: Barriers and Facilitators. J Int Assoc Provid AIDS Care JIAPAC. 2017 3;16(2):180-8. [PubMed: 28325130]

14. Mellins CA, Chu C, Malee K, Allison S, Smith R, Harris L, et al. Adherence to antiretroviral treatment among pregnant and postpartum HIV-infected women. AIDS Care. 2008 9;20(8):95868. [PubMed: 18608073]

15. Iyun V, Brittain K, Phillips TK, le Roux S, McIntyre JA, Zerbe A, et al. Prevalence and determinants of unplanned pregnancy in HIV-positive and HIV-negative pregnant women in Cape Town, South Africa: a cross-sectional study. BMJ Open. 2018 4;8(4):e019979.

16. Singer AW, Weiser SD, McCoy SI. Does Food Insecurity Undermine Adherence to Antiretroviral Therapy? A Systematic Review. AIDS Behav. 2015 8;19(8):1510-26. [PubMed: 25096896]

17. McMahon JH, Wanke CA, Elliott JH, Skinner S, Tang AM. Repeated Assessments of Food Security Predict CD4 Change in the Setting of Antiretroviral Therapy: JAIDS J Acquir Immune Defic Syndr. 2011 9;58(1):60-3. [PubMed: 21694604]

18. Nagata JM, Magarenge R, Young SL, Oguta J, Weiser SA, Cohen CR. Social determinants, lived experiences, and consequences of household food insecurity among persons living with HIV/AIDS on the shore of Lake Victoria, Kenya. AIDS Care. 2012;24(6):728-36. [PubMed: 22150119]

19. Hong SY, Fanelli TJ, Jonas A, Gweshe J, Tjituka F, Sheehan HMB, et al. Household Food Insecurity Associated With Antiretroviral Therapy Adherence Among HIV-Infected Patients in Windhoek, Namibia: JAIDS J Acquir Immune Defic Syndr. 2014 12;67(4):e115-22. [PubMed: 25356779]

20. Kalichman SC, Grebler T, Amaral CM, McKerney M, White D, Kalichman MO, et al. Food insecurity and antiretroviral adherence among HIV positive adults who drink alcohol. J Behav Med. 2014 10;37(5):1009-18. [PubMed: 24022091]

21. Chop E, Duggaraju A, Malley A, Burke V, Caldas S, Yeh PT, et al. Food insecurity, sexual risk behavior, and adherence to antiretroviral therapy among women living with HIV: A systematic review. Health Care Women Int. 2017 9 2;38(9):927-44. [PubMed: 28586273]

22. Young S, Wheeler AC, McCoy SI, Weiser SD. A Review of the Role of Food Insecurity in Adherence to Care and Treatment Among Adult and Pediatric Populations Living with HIV and AIDS. AIDS Behav. 2014 10;18(S5):505-15. [PubMed: 24469223]

23. Aibibula W, Cox J, Hamelin A-M, Mamiya H, Klein MB, Brassard P. Food insecurity and low CD4 count among HIV-infected people: a systematic review and meta-analysis. AIDS Care. 2016 12;28(12):1577-85. [PubMed: 27306865] 
24. Leddy AM, Sheira LA, Tamraz B, Sykes C, Kashuba ADM, Wilson TE, et al. Food insecurity is associated with lower levels of antiretroviral drug concentrations in hair among a cohort of women living with HIV in the United States. Clin Infect Dis. 201910 14;ciz1007.

25. Weiser SD, Tuller DM, Frongillo EA, Senkungu J, Mukiibi N, Bangsberg DR. Food Insecurity as a Barrier to Sustained Antiretroviral Therapy Adherence in Uganda. PLOS ONE. 20104 28;5(4):e10340.

26. Tsai AC, Bangsberg DR, Frongillo EA, Hunt PW, Muzoora C, Martin JN, et al. Food insecurity, depression and the modifying role of social support among people living with HIV/AIDS in rural Uganda. Soc Sci Med. 2012 6;74(12):2012-9. [PubMed: 22513248]

27. Vyavaharkar M, Moneyham L, Tavakoli A, Phillips KD, Murdaugh C, Jackson K, et al. Social Support, Coping, and Medication Adherence Among HIV-Positive Women with Depression Living in Rural Areas of the Southeastern United States. AIDS Patient Care STDs. 2007 9;21(9):667-80. [PubMed: 17919094]

28. Kelly JD, Hartman C, Graham J, Kallen MA, Giordano TP. Social Support as a Predictor of Early Diagnosis, Linkage, Retention, and Adherence to HIV Care: Results From The Steps Study. J Assoc Nurses AIDS Care. 2014 9;25(5):405-13. [PubMed: 24508174]

29. Carballo. Assessing relationships between health-related quality of life and adherence to antiretroviral therapy.

30. Mannheimer SB, Matts J, Telzak E, Chesney M, Child C, Wu AW, et al. Quality of life in HIVinfected individuals receiving antiretroviral therapy is related to adherence. AIDS Care. 2005 1;17(1):10-22. [PubMed: 15832830]

31. Vagiri RV, Meyer JC, Gous AGS. Health-related quality of life and adherence to antiretroviral treatment over a 12-month period for patients attending two public sector clinics in South Africa. : 13 .

32. Whetten K, Shirey K, Pence BW, Yao J, Thielman N, Whetten R, et al. Trauma History and Depression Predict Incomplete Adherence to Antiretroviral Therapies in a Low Income Country. PLOS ONE. 201310 4;8(10):e74771.

33. Usitalo A, Leister E, Tassiopoulos K, Allison S, Malee K, Paul ME, et al. Relationship between viral load and self-report measures of medication adherence among youth with perinatal HIV infection. AIDS Care. 2014 1;26(1):107-15. [PubMed: 23800360]

34. Bottonari KA, Safren SA, McQuaid JR, Hsiao C-B, Roberts JE. A longitudinal investigation of the impact of life stress on HIV treatment adherence. J Behav Med. 2010 12;33(6):486-95. [PubMed: 20577794]

35. Turan B, Smith W, Cohen MH, Wilson TE, Adimora AA, Merenstein D, et al. Mechanisms for the Negative Effects of Internalized HIV-Related Stigma on Antiretroviral Therapy Adherence in Women: The Mediating Roles of Social Isolation and Depression. J Acquir Immune Defic Syndr 1999. 20166 1;72(2):198-205.

36. Kabore L, Muntner P, Chamot E, Zinski A, Burkholder G, Mugavero MJ. Self-Report Measures in the Assessment of Antiretroviral Medication Adherence: Comparison with Medication Possession Ratio and HIV Viral Load. J Int Assoc Provid AIDS Care JIAPAC. 2015 3;14(2):156-62. [PubMed: 25421930]

37. Berg KM, Arnsten JH. Practical and Conceptual Challenges in Measuring Antiretroviral Adherence: JAIDS J Acquir Immune Defic Syndr. 2006 12;43(Supplement 1):S79-87. [PubMed: 17133207]

38. Alcaide ML, Ramlagan S, Rodriguez VJ, Cook R, Peltzer K, Weiss SM, et al. Self-Report and Dry Blood Spot Measurement of Antiretroviral Medications as Markers of Adherence in Pregnant Women in Rural South Africa. AIDS Behav. 2017 7;21(7):2135-40. [PubMed: 28361454]

39. Baxi SM, Greenblatt RM, Bacchetti P, Jin C, French AL, Keller MJ, et al. Nevirapine Concentration in Hair Samples Is a Strong Predictor of Virologic Suppression in a Prospective Cohort of HIV-Infected Patients. Garcia-Lerma JG, editor. PLOS ONE. 20156 8;10(6):e0129100.

40. Gandhi M, Ameli N, Bacchetti P, Anastos K, Gange SJ, Minkoff H, et al. Atazanavir Concentration in Hair Is the Strongest Predictor of Outcomes on Antiretroviral Therapy. Clin Infect Dis Off Publ Infect Dis Soc Am. 20115 15;52(10):1267-75. 
41. Gandhi M, Ameli N, Bacchetti P, Gange SJ, Anastos K, Levine A, et al. Protease inhibitor levels in hair strongly predict virologic response to treatment: AIDS. 2009 2;23(4):471-8. [PubMed: 19165084]

42. Koss CA, Natureeba P, Mwesigwa J, Cohan D, Nzarubara B, Bacchetti P, et al. Hair Concentrations of Antiretrovirals Predict Viral Suppression in HIV-Infected Pregnant and Breastfeeding Ugandan Women. AIDS Lond Engl. 20154 24;29(7):825-30.

43. Pintye J, Bacchetti P, Teeraananchai S, Kerr S, Prasitsuebsai W, Singtoroj T, et al. Brief Report: Lopinavir Hair Concentrations Are the Strongest Predictor of Viremia in HIV-Infected Asian Children and Adolescents on Second-Line Antiretroviral Therapy. JAIDS J Acquir Immune Defic Syndr. 2017 12;76(4):367-71. [PubMed: 28825944]

44. Prasitsuebsai W, Kerr SJ, Truong KH, Ananworanich J, Do VC, Nguyen LV, et al. Using Lopinavir Concentrations in Hair Samples to Assess Treatment Outcomes on Second-Line Regimens Among Asian Children. AIDS Res Hum Retroviruses. 2015 10;31(10):1009-14. [PubMed: 26200586]

45. Tabb ZJ, Mmbaga BT, Gandhi M, Louie A, Kuncze K, Okochi H, et al. Antiretroviral drug concentrations in hair are associated with virologic outcomes among young people living with HIV in Tanzania: AIDS. 2018 6;32(9):1115-23. [PubMed: 29438196]

46. van Zyl GU, van Mens TE, McIlleron H, Zeier M, Nachega JB, Decloedt E, et al. Low Lopinavir Plasma or Hair Concentrations Explain Second-Line Protease Inhibitor Failures in a ResourceLimited Setting: JAIDS J Acquir Immune Defic Syndr. 2011 4;56(4):333-9. [PubMed: 21239995]

47. Koss CA, Hosek SG, Bacchetti P, Anderson PL, Liu AY, Horng H, et al. Comparison of Measures of Adherence to Human Immunodeficiency Virus Preexposure Prophylaxis Among Adolescent and Young Men Who Have Sex With Men in the United States. Clin Infect Dis. 20181 6;66(2):213-9. [PubMed: 29020194]

48. Hickey MD, Salmen CR, Tessler RA, Omollo D, Bacchetti P, Magerenge R, et al. Antiretroviral concentrations in small hair samples as a feasible marker of adherence in rural Kenya. J Acquir Immune Defic Syndr 1999. 20147 1;66(3):311-5.

49. Wu G, Zaman MH. Low-cost tools for diagnosing and monitoring HIV infection in low-resource settings. Bull World Health Organ. 201212 1;90(12):914-20. [PubMed: 23284197]

50. Murnane PM, Bacchetti P, Currier JS, Brummel S, Okochi H, Phung N, et al. Tenofovir concentrations in hair strongly predict virologic suppression in breastfeeding women: AIDS. 2019 $4 ; 1$.

51. Gandhi M, Devi S, Bacchetti P, Chandy S, Heylen E, Phung N, et al. Measuring Adherence to Antiretroviral Therapy via Hair Concentrations in India: JAIDS J Acquir Immune Defic Syndr. 2019 6;81(2):202-6. [PubMed: 30865182]

52. Natamba BK, Kilama H, Arbach A, Achan J, Griffiths JK, Young SL. Reliability and validity of an individually focused food insecurity access scale for assessing inadequate access to food among pregnant Ugandan women of mixed HIV status. Public Health Nutr. 2015 11;18(16):2895-905. [PubMed: 25171462]

53. Ndege S, Washington S, Kaaria A, Prudhomme-O'Meara W, Were E, Nyambura M, et al. HIV Prevalence and Antenatal Care Attendance among Pregnant Women in a Large Home-Based HIV Counseling and Testing Program in Western Kenya. Correa-Velez I, editor. PLOS ONE. 20161 19;11(1):e0144618.

54. Demographic Kenya and Survey Health 2014. Nairobi, Kenya: Kenya National Bureau of Statistics, Kenya MOH, National AIDS Control Council, Kenya Medical Research Institute KEMRI, National Council for Population and Development, ICF International; 201512.

55. Kenya AIDS Response Progress Report 2018. Nairobi, Kenya: National AIDS Control Council, Kenya Ministry of Health; 2018.

56. Antelman G, Smith Fawzi MC, Kaaya S, Mbwambo J, Msamanga GI, Hunter DJ, et al. Predictors of HIV-1 serostatus disclosure: a prospective study among HIV-infected pregnant women in Dar es Salaam, Tanzania: AIDS. 2001 9;15(14):1865-74.

57. Ware NC, Idoko J, Kaaya S, Biraro IA, Wyatt MA, Agbaji O, et al. Explaining Adherence Success in Sub-Saharan Africa: An Ethnographic Study. Beyrer C, editor. PLoS Med. 20091 27;6(1):e1000011. 
58. Natamba BK, Achan J, Arbach A, Oyok TO, Ghosh S, Mehta S, et al. Reliability and validity of the center for epidemiologic studies-depression scale in screening for depression among HIVinfected and -uninfected pregnant women attending antenatal services in northern Uganda: a crosssectional study. BMC Psychiatry [Internet]. 20141122 [cited 2017 Nov 8];14. Available from: https://www.ncbi.nlm.nih.gov/pmc/articles/PMC4260190/

59. Earnshaw VA, Smith LR, Chaudoir SR, Amico KR, Copenhaver MM. HIV Stigma Mechanisms and Well-Being Among PLWH: A Test of the HIV Stigma Framework. AIDS Behav. 2013 6;17(5):1785-95. [PubMed: 23456594]

60. Garcia-Moreno C, Organizacion Mundial de la Salud. WHO multi-country study on women's health and domestic violence against women: initial results on prevalence, health outcomes and women's responses. Ginebra: Organización Mundial de la Salud; 2005.

61. DiFrancesco R, Tooley K, Rosenkranz SL, Siminski S, Taylor CR, Pande P, et al. Clinical Pharmacology Quality Assurance for HIV and Related Infectious Diseases Research. Clin Pharmacol Ther. 2013 6;93(6):479-82. [PubMed: 23588323]

62. Fairchild AJ, MacKinnon DP. A General Model for Testing Mediation and Moderation Effects. Prev Sci. 2009 6;10(2):87-99. [PubMed: 19003535]

63. Weiser SD, Palar K, Frongillo EA, Tsai AC, Kumbakumba E, dePee S, et al. Longitudinal assessment of associations between food insecurity, antiretroviral adherence and HIV treatment outcomes in rural Uganda: AIDS. 2014 1;28(1):115-20. [PubMed: 23939234]

64. Cassel J. The contribution of the social environment to host resistance. Am J Epidemiol. 1976 8;104(2):107-23. [PubMed: 782233]

65. Cobb S. Social Support as a Moderator of Life Stress: Psychosom Med. 1976 9;38(5):300-14. [PubMed: 981490]

66. Cohen S, Wills T. Stress, social support, and the buffering hypothesis. Psychol Bull. 1985 9;98(2):310-57. [PubMed: 3901065]

67. Kollannoor-Samuel G, Wagner J, Damio G, Segura-Pérez S, Chhabra J, Vega-López S, et al. Social Support Modifies the Association Between Household Food Insecurity and Depression Among Latinos with Uncontrolled Type 2 Diabetes. J Immigr Minor Health. 2011 12;13(6):982-9. [PubMed: 21789561]

68. Kapulsky L, Tang AM, Forrester JE. Food Insecurity, Depression, and Social Support in HIVInfected Hispanic Individuals. J Immigr Minor Health. 2015 4;17(2):408-13. [PubMed: 25047405]

69. Lehavot K, Huh D, Walters KL, King KM, Andrasik MP, Simoni JM. Buffering Effects of General and Medication-Specific Social Support on the Association Between Substance Use and HIV Medication Adherence. AIDS Patient Care STDs. 2011 3;25(3):181-9. [PubMed: 21375430]

70. Cutrona C, Suhr J. Controllability of stressful events and satisfaction with spouse support behaviors. Commun Res. 1992;154-74.

71. Sin NL, DiMatteo MR. Depression Treatment Enhances Adherence to Antiretroviral Therapy: a Meta-Analysis. Ann Behav Med. 2014 6;47(3):259-69. [PubMed: 24234601] 


\section{ILLUSTRATIONS}
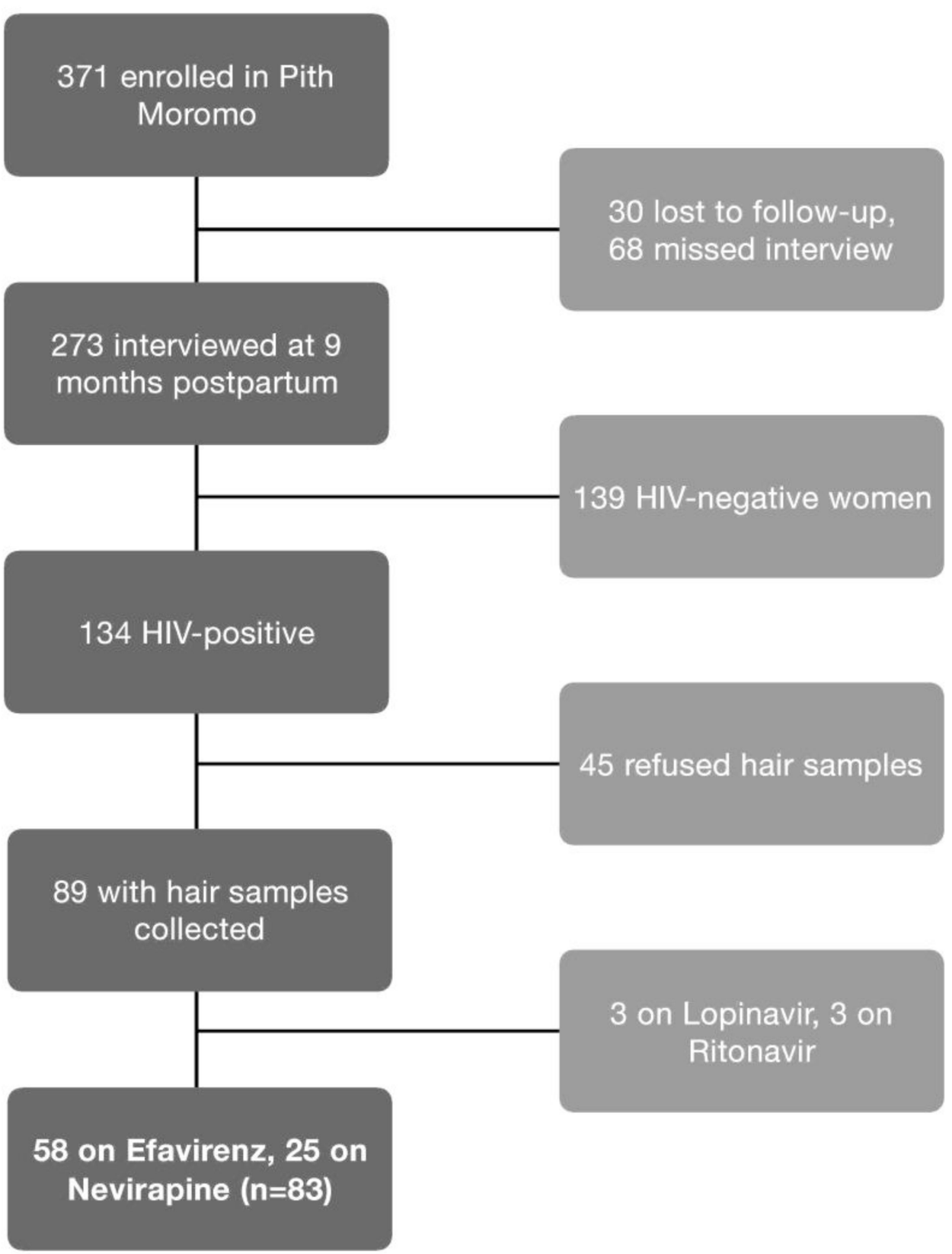

Figure 1:

Study flow of participants through Pith Moromo. In this ART adherence sub-study, we restricted our analysis to 83 women who provided hair samples and were on efavirenz- or nevirapine-based ART regimens at nine months postpartum. 
4

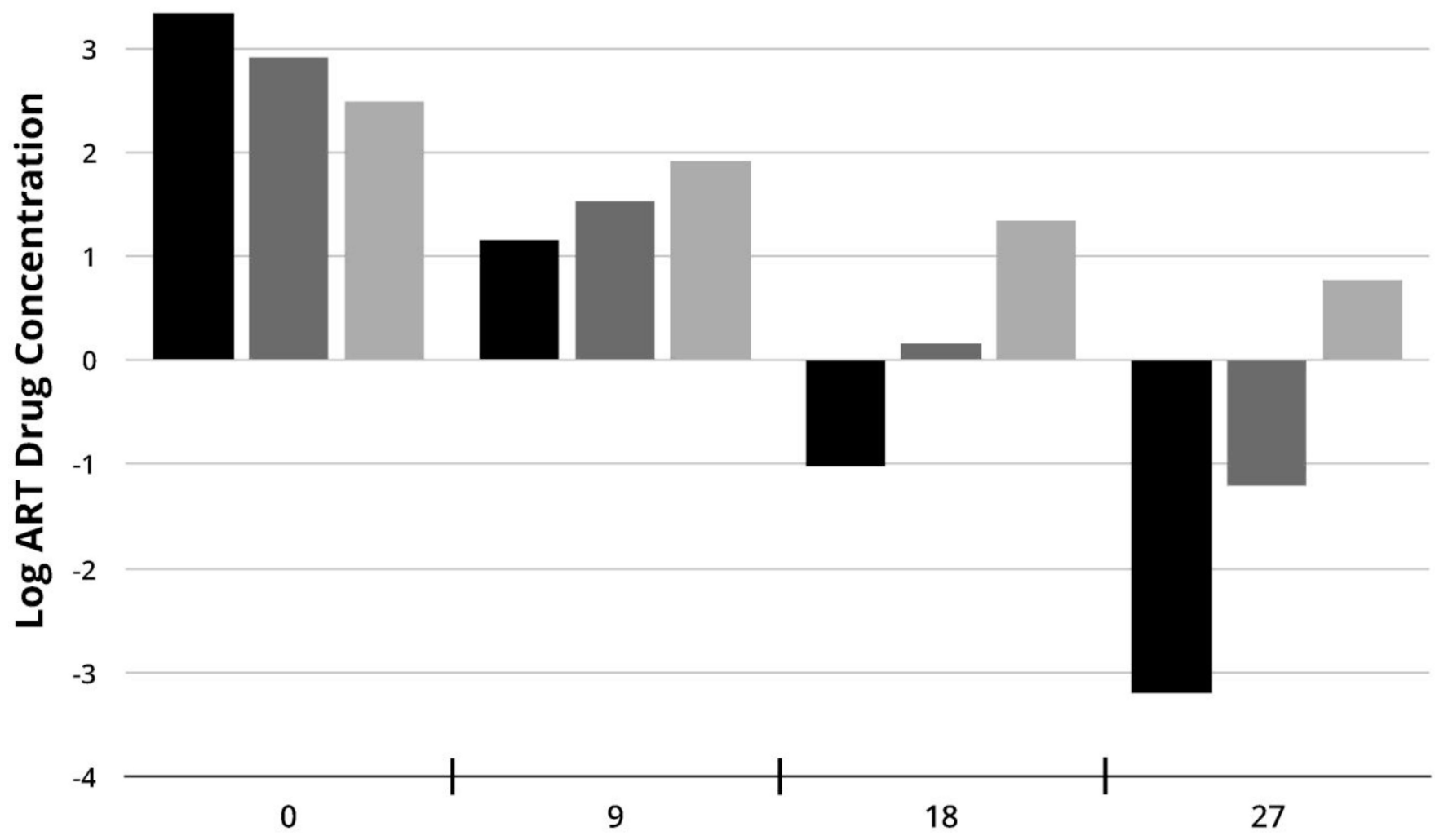

Individual Food Insecurity Score

Figure 2:

Predicted log change in ART drug concentration by social support and food insecurity. Increased social support was predicted to attenuate the negative impact of food insecurity on ART drug concentration $(\mathrm{n}=81)$. 
Table I.

Characteristics of participants who provided hair samples at nine months postpartum, by ART drug regimen $(n=83)$.

\begin{tabular}{|c|c|c|c|}
\hline & Efavirenz $(n=58)$ & Nevirapine (n=25) & Combined $(n=83)$ \\
\hline Married, \% & 86.2 & 96.0 & 89.2 \\
\hline Maternal age, median (IQR) & $25.0(7.0)$ & $28.0(6.0)$ & $26.0(8.0)$ \\
\hline \multicolumn{4}{|l|}{ Education level, \% } \\
\hline Primary or less & 57.9 & 84.0 & 65.9 \\
\hline Secondary & 38.6 & 12.0 & 30.5 \\
\hline More than secondary & 3.5 & 4.0 & 3.7 \\
\hline \multicolumn{4}{|l|}{ Ethnic group, \% } \\
\hline Luo & 96.3 & 96.0 & 96.2 \\
\hline Luhya & 3.7 & 4.0 & 3.8 \\
\hline Asset index, median (IQR) & $0.1(2.6)$ & $-0.6(2.3)$ & $-0.2(2.6)$ \\
\hline Dependency ratio, mean (sd) & $0.7(0.2)$ & $0.7(0.2)$ & $0.7(0.2)$ \\
\hline Minutes to clinic, median (IQR) & $40.0(40.0)$ & $40.0(60.0)$ & $40.0(30.0)$ \\
\hline Food insecurity score, mean (sd) & $10.1(5.3)$ & $9.7(4.9)$ & $10.0(5.2)$ \\
\hline Maternal depression score, mean (sd) & $9.0(8.6)$ & $7.0(6.9)$ & $8.4(8.1)$ \\
\hline Any probable depression, $\%$ & 17.2 & 8.0 & 14.5 \\
\hline Maternal HIV stigma score, mean (sd) & $26.7(6.2)$ & $24.6(3.9)$ & $26.1(5.7)$ \\
\hline Maternal stress score, mean (sd) & $17.5(4.2)$ & $17.0(4.1)$ & $17.4(4.1)$ \\
\hline Social support score, mean (sd) & $28.1(6.2)$ & $31.8(6.6)$ & $29.2(6.5)$ \\
\hline Hair ART drug concentration (ng/mg), median (IQR) & $3.0(0.25-11.0)$ & $60.0(33.4-79.7)$ & - \\
\hline
\end{tabular}


Table II.

Bivariate associations between selected characteristics and logarithmically transformed hair ART drug concentrations among women living with HIV in western Kenya $(n=83)$.

\begin{tabular}{|c|c|c|}
\hline \multirow[b]{3}{*}{ Health Indicators } & \multicolumn{2}{|c|}{ Log Hair ART Drug Concentration } \\
\hline & \multirow[t]{2}{*}{ Coefficient (95\% CI) } & \multirow[t]{2}{*}{$p$-value } \\
\hline & & \\
\hline Food insecurity score $(n=82)$ & $-0.16(-0.25,-0.07)$ & 0.001 \\
\hline Quality of life score $(n=83)$ & $0.16(0.06,0.25)$ & 0.001 \\
\hline Social support score $(\mathrm{n}=83)$ & $0.14(0.07,0.21)$ & $<0.001$ \\
\hline Depression score $(n=83)$ & $-0.004(-0.07,0.05)$ & 0.894 \\
\hline Any probable depression $(\mathrm{n}=83)$ & $-0.14(-1.58,1.30)$ & 0.847 \\
\hline Disclosed status to partner $(n=83)$ & $0.44(-0.64,1.52)$ & 0.416 \\
\hline Newly diagnosed with HIV at enrollment (vs. known positive) $(n=82)$ & $-1.07(-2.06,-0.08)$ & 0.033 \\
\hline Maternal HIV stigma score $(n=57)$ & $0.01(-0.09,0.11)$ & 0.886 \\
\hline Maternal stress score $(n=83)$ & $-0.05(-0.17,0.08)$ & 0.446 \\
\hline Experienced gender-based violence $(n=83)$ & $-0.05(-1.37,1.27)$ & 0.937 \\
\hline Perceived social standing in the community $(n=83)$ & $0.05(-0.26,0.36)$ & 0.746 \\
\hline Perceived social standing in the country $(n=83)$ & $0.04(-0.26,0.34)$ & 0.795 \\
\hline \multicolumn{3}{|l|}{ Sociodemographic Characteristics } \\
\hline Married (vs. single) $(n=83)$ & $0.70(-0.93,2.32)$ & 0.396 \\
\hline Maternal age $(n=83)$ & $0.06(-0.03,0.14)$ & 0.201 \\
\hline Primigravid $(\mathrm{n}=81)$ & $-0.05(-1.68,1.57)$ & 0.947 \\
\hline \multicolumn{3}{|l|}{ Education level $(n=82)$} \\
\hline Primary or less & ref. & ref. \\
\hline Secondary & $-0.28(-1.41,0.85)$ & 0.624 \\
\hline More than secondary & $0.94(-1.82,3.70)$ & 0.500 \\
\hline Asset index $(\mathrm{n}=83)$ & $0.27(-0.04,0.58)$ & 0.082 \\
\hline Dependency ratio $(n=71)$ & $1.08(-2.35,4.51)$ & 0.532 \\
\hline \multicolumn{3}{|l|}{ Ethnic group $(n=79)$} \\
\hline Luo & ref. & ref. \\
\hline Luhya & $1.66(-1.01,4.33)$ & 0.220 \\
\hline Minutes to clinic $(n=80)$ & $0.006(-0.005,0.02)$ & 0.263 \\
\hline
\end{tabular}

AIDS Behav. Author manuscript; available in PMC 2021 October 01. 


\section{Table III.}

Comparison of models predicting hair ART drug concentration among women living with HIV in western Kenya, with and without an interaction term $(n=81)$.

\begin{tabular}{|c|c|c|c|c|}
\hline & \multicolumn{2}{|c|}{$\begin{array}{l}\text { Model 1: } \\
\text { no interaction term }\end{array}$} & \multicolumn{2}{|c|}{$\begin{array}{l}\text { Model 2: } \\
\text { interaction between food insecurity and social support }\end{array}$} \\
\hline & Coefficient $(95 \%$ CI $)$ & $p$-value & Coefficient $(95 \%$ CI $)$ & $p$-value \\
\hline Asset index & $0.16(-0.13,0.46)$ & 0.277 & $0.21(-0.08,0.50)$ & 0.158 \\
\hline $\begin{array}{l}\text { Newly diagnosed with HIV at enrollment } \\
\text { (vs. known positive) }\end{array}$ & $-1.07(-1.97,-0.18)$ & 0.020 & $-0.94(-1.82,-0.06)$ & 0.037 \\
\hline Quality of life score & $0.12(0.02,0.21)$ & 0.016 & $0.10(0.01,0.20)$ & 0.028 \\
\hline Food insecurity score & $-0.09(-0.20,0.02)$ & 0.113 & $-0.60(-1.03,-0.17)$ & 0.007 \\
\hline Social support score & $0.06(-0.03,0.14)$ & 0.181 & $-0.09(-0.23,0.06)$ & 0.241 \\
\hline Social support $*$ food insecurity & & & $0.02(0.003,0.03)$ & 0.017 \\
\hline \multicolumn{5}{|l|}{ Model fit } \\
\hline Adjusted $\mathrm{R}^{2}$ & 0.25 & & 0.29 & \\
\hline Root mean square error (RMSE) & 2.00 & & 1.94 & \\
\hline
\end{tabular}

